$\begin{array}{ll} & \text { Etnográfica } \\ \text { etnográfica } & \text { Revista do Centro em Rede de Investigação em }\end{array}$

Antropologia

vol. 12 (1) | 2008

Vol. $12(1)$

\title{
Recorrências antroponímicas lusófonas
}

Lusophone anthroponymy recurrences

\section{João de Pina-Cabral}

\section{OpenEdition \\ Journals}

\section{Edição electrónica}

URL: https://journals.openedition.org/etnografica/1684

DOI: 10.4000/etnografica. 1684

ISSN: 2182-2891

\section{Editora}

Centro em Rede de Investigação em Antropologia

\section{Edição impressa}

Data de publição: 1 maio 2008

Paginação: 237-262

ISSN: 0873-6561

Refêrencia eletrónica

João de Pina-Cabral, «Recorrências antroponímicas lusófonas», Etnográfica [Online], vol. 12 (1) | 2008, posto online no dia 20 junho 2012, consultado o 12 fevereiro 2022. URL: http://

journals.openedition.org/etnografica/1684 ; DOI: https://doi.org/10.4000/etnografica.1684

Este documento foi criado de forma automática no dia 12 fevereiro 2022.

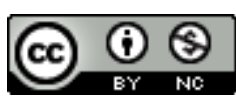

Etnográfica is licensed under a Creative Commons Attribution-NonCommercial 4.0 International License. 


\section{Recorrências antroponímicas lusófonas}

Lusophone anthroponymy recurrences

João de Pina-Cabral

\section{A pessoa nomeada}

1 Os nomes pelos quais somos conhecidos e chamados constituem um aspecto central da nossa condição de pessoa - não só de quem somos para os outros, mas ainda de quem somos para nós mesmos, já que as duas coisas estão profundamente interligadas. Ninguém tem um só nome, nem o usa sempre da mesma forma, nem as diferentes pessoas com que nos cruzamos presumem as mesmas coisas sobre o nosso nome. Os nomes de pessoa, por muito que sejam um universal da condição humana, diferenciam as pessoas de muitas e diversas formas.

2 Para além disso, a antroponímia está sujeita a grandes padrões que se vão formando na longa duração da história. Estas recorrências antroponímicas correspondem a vectores estruturantes de uma forma de ser pessoa que é veiculada no interior de tradições socioculturais que vão evoluindo com o tempo. Elas constituem regimes antroponímicos cuja identificação requer um exercício de comparação controlada, quer dizer, uma comparação por contraste.

Num ensaio exemplar sobre o assunto, Richard Fardon explica:

a prática da comparação envolve explorar as confluências em que nos reconhecemos tanto a nós próprios como aos outros. Em vez da comparação ser o método da antropologia, aquilo que se compara e como se compara, depende da história do "onde" se está a comparar. [...] Misturando os horizontes da comparação etnográfica e da comparação histórica, permite-nos compreender como e porque é que o presente de uma região [...] se constrói. (1996: 32)

4 Tem razão, na medida em que o processo comparativo se baseia num encadeamento e cruzamento de contrastes. Poderíamos pensar, portanto, que o processo teria o seu início no próprio momento etnográfico e chegaria ao seu fim na postulação de um 
contexto histórico regional. Num primeiro momento, poderia parecer que uma tal aproximação contrastiva nos libertaria da necessidade de recorrer a categorias analíticas externas ao contexto a comparar; partiríamos da autocomparação nativa para a comparação científica. Mas a solução é artificiosa. Em primeiro lugar, não é no momento da etnografia que iniciamos o processo comparativo - pelo contrário, é a comparação que nos leva à etnografia, porque esta última só se justifica como resposta a uma suspeita de que há algo, e de um certo tipo, a conhecer. A história das ciências sociais e humanas ultrapassa em muito uma cadeia contrastiva do tipo acima descrito. Em segundo lugar, se fôssemos a depender unicamente de tais cadeias, cedo encontraríamos muros intransponíveis, becos sem saída para o prosseguimento da nossa tarefa.

5 Em suma, sem a postulação de parâmetros de importância relativa - isto é, vectores analíticos que permitam escolher um ângulo comparativo - não seríamos capazes de propor qualquer regionalidade, já que a simples contiguidade geográfica seria insuficiente. ${ }^{1}$ A comparação controlada, seja ela qual for, envolve sempre um movimento duplo vagamente paradoxal: por um lado, ascendente - da observação etnográfica em direcção a modelos regionais e supra--regionais; por outro lado, descendente - dos conceitos analíticos abstractos constituídos a partir de modelos formais para a prática vivida da complexidade histórica. Mesmo quando não é claramente explicitado, este movimento duplo, enquanto metodologia comparativa, liga a empiria à teoria numa oscilação constante que tem sido, de facto, a principal força motora por trás da antropologia. Por isso, numa tentativa de examinar a antroponímia lusófona somos obrigados a partir do conceito abstracto de pessoa nomeada.

\section{Uma regionalidade antroponímica}

6 As disposições comparativistas que herdámos do século XX tendem a enfatizar a contiguidade espacial como constituinte central da regionalidade sociocultural. Presume-se que os processos de densidade sociocultural que evoluem historicamente são necessariamente contíguos de um ponto de vista espacial - um "povo", "nação", "sociedade", "grupo" são coisas essencialmente contíguas. Acontece que a contiguidade espacial nem sempre é o melhor ângulo para captar a regionalidade. Vejam-se os casos europeus dos judeus ou dos ciganos - onde processos diaspóricos de natureza distinta, associados a situações de marginalidade estrutural constituíram complexos socioculturais de longo prazo cuja regionalidade assentou sempre sobre nexos de deslocação e não de radicação territorial.

7 Urge, pois, ultrapassar o sedentarismo comparativo e procurar regionalidades transnacionais. Para tal, porém, há que endereçar também o problema central do comparativismo sociológico modernista: o seu sociocentrismo. De facto, a tendência é para basear o comparativismo regional em entidades sociais supostamente autoreferenciadas: nações, culturas, povos, religiões. No entanto, a Época Moderna e a modernidade legaram-nos uma série de processos resultantes das expansões imperiais que acabaram por constituir densidades socioculturais descontínuas (cf. Sansi-Roca 2007). Assim, verificam-se processos de encadeamento sociocultural de longo prazo (regionalidades) cujas implicações são muitas vezes escondidas, por um lado, por uma pulsão ideológica que atribui mais peso às lógicas de entidades políticas auto- 
referenciadas (o nacionalismo), por outro lado, por uma pulsão ideológica de pendor hegemonista que atribui uniformidade global aos processos identificados com a modernidade (a apologia da globalização). A proposta central deste ensaio é que o facto de haver gente em muitas partes do mundo cujo nome foi constituído e é utilizado por relação a uma tradição antroponímica lusófona constitui um desses fenómenos de regionalidade sociocultural de médio alcance.

8 No presente ensaio, procurei identificar as recorrências mais comuns e estruturantes na tradição lusófona de constituição de nomes de pessoa $^{2}$ no pressuposto de que estas afectam as pessoas que os usam; concedendo-lhes, assim, alguma semelhança. Tal como todas as outras regionalidades, não está aqui em causa captar identidades absolutas, mas sim identificar parâmetros contrastivos que constituam campos de diversificação sociocultural. O que se pode ou deve fazer com um nome (isto é, como ele pode ou deve ser legitimamente usado) não é universal, nem os nossos nomes modernos são todos constituídos da mesma forma. Por um lado, há fortes implicações na adopção de nomes portugueses por parte de populações que até aí não os usavam desta forma (como demonstram tão bem os ensaios de Ramos, Trajano Filho e Feijó, neste volume). Por outro lado, mesmo na Europa Ocidental, existe uma grande diversidade antroponímica - ser chamado por um nome constituído na tradição da Common Law carrega consigo implicações distintas de usar um nome em português.

9 A antroponímia lusófona moderna transporta implicações sobre a inserção social da pessoa porque está imersa numa longa história social. Essa história não está só causalmente ligada aos nossos nomes - como se fosse algo que aconteceu no passado mas que já não actua. Pelo contrário, trata-se de uma preteridade que continua a ser relevante, isto é, a história dos nomes que usamos faz parte da maneira como hoje usamos esses nomes e isso é claramente exemplificado no desenho do processo que fazem os vários contribuintes para este número temático.

10 Estes princípios antroponímicos operam diferenciadamente em contextos sóciohistóricos distintos. A regionalidade constituída pela antroponímia lusófona é, por sua vez, um excelente campo para o exercício da comparação contrastiva. Mais uma vez aqui vemos os dois movimentos em funcionamento: por um lado, o exercício pode ajudar-nos a questionar as categorias analíticas da antropologia (tais como pessoa, género, família, parentesco, processo, estrutura, margem, etc.) e, por outro lado, essas mesmas categorias são o que permite aprofundar de formas inovadoras essa procura comparativa.

11 Os esforços que tenho vindo a realizar de identificação do funcionamento e implicações sociais dos nomes de pessoa em contextos lusófonos ${ }^{3}$ apontam para três grandes vectores estruturantes: o nome duplo, o nome verdadeiro e o nome sexuado. Note-se, desde já, que estes não são necessariamente exclusivos da lusofonia. Não só fazem parte de um grande sistema ibérico como são até relevantes ao nível mais abrangente da Europa e mesmo de toda a Eurásia. É no jogo de contrastes no interior desse processo comparativo que está a riqueza do exercício de comparação controlada.

\section{O nome duplo}

12 O nome de pessoa lusófono divide-se em duas partes: uma que distingue a pessoa na sua unicidade (nome próprio) e outra que a distingue na sua inserção familiar (sobrenome). 
Assim, apesar de o nome pessoal como um todo ser um nome próprio, no seu interior o sobrenome funciona, de facto, como um nome de espécie.

Esta diferença reflecte-se na própria natureza das palavras mais escolhidas para funcionar como nome próprio e como sobrenome: os primeiros são tendencialmente metafóricos e os segundos metonímicos. Isto é, o nome próprio qualifica a pessoa em termos de santos, de heróis, de valores exaltados ou de princípios de excelência; o sobrenome integra a pessoa de forma descritiva por relação a uma profissão - p. ex., Monteiro, Cutileiro; por relação a um antepassado - p. ex. Henriques, Eanes, Afonso ou Lourenço; mas, sobretudo, por relação a uma casa ou uma terra que, por sua vez, podem ser nomeadas de formas muito diversas - p. ex. Oliveira, Sobral, Almeida, Cabral. A ligação heráldica dos sobrenomes com os símbolos que os representam (Cabral com cabras, Pina com pinheiros, Costa com costelas) é vaga e secundária e, em muitos casos, nem sequer presumida (quando Pina, por exemplo, é representado por uma torre ou Pereira por uma cruz).

A cultura popular desinteressa-se pelas implicações metafóricas dos sobrenomes mas demonstra um fascínio persistente pela etimologia do nome próprio, pelo seu "significado", pelas suas implicações sonoras, pelos seus ecos mediáticos. Os sobrenomes são relevantes não pelas conotações que transportam mas pelas associações que fazem (a famílias, a profissões, a terras, a classes, a castas). Por exemplo, em Macau, nos anos 80 e 90, os portugueses ficavam surpreendidos ao descobrir que, para os chineses, os nomes dos governadores eram uma fonte de chacota: pinto, machado, melancia, murteira, nabo, rocha, vieira pareciam aos chineses termos pouco nobres para qualificar oficiais tão importantes. Para os portugueses, porém, a questão não se levantava, já que esses sobrenomes não qualificavam semanticamente as pessoas que os transportavam mas qualificavam associativamente, integrando-as num grupo. Era mais relevante, portanto, que Rocha Vieira ou Pinto Machado fossem sobrenomes que sugerem uma origem burguesa enquanto Melancia ou Nabo sugerem uma origem popular. Por isso, não encontramos nenhum empenho especial em evitar que os sobrenomes sejam "cómicos" ou "indecorosos" - as suas conotações passam geralmente por irrelevantes, ${ }^{4}$ contrariamente ao que acontece com o nome próprio.

O nome próprio é o "nome de pia" (baptismal) que, à luz da tradição cristã, transporta a sacralidade da pessoa humana, qualificando-a no que tem de mais essencial. É o nome da alma. Já o sobrenome adjectiva a pessoa ligando-a a um contexto de pertença social, a estruturas de poder e processos burocráticos. Como sublinha Ana Maria Machado, "A referência por meio de títulos e sobrenomes se associa a uma estabilidade que acompanha a propriedade, a inatividade de quem possui, mas não faz." (1991: 44) A oposição entre nome próprio e sobrenome é associada à oposição entre ser e ter, respectivamente. Assim, entre as classes médias portuguesas e brasileiras, a preocupação com o sobrenome (nomeadamente a adopção de sobrenomes duplos) está ligada a fenómenos de promoção social e à existência de propriedade que é passada na linha familiar. Pelo contrário, certos sobrenomes transportam uma marca de subalternidade original. Note-se, aliás, que as instâncias em que um nome próprio é usado como nome familiar são instâncias que frequentemente subalternizam a família, sugerindo uma origem familiar em alguém que "não tinha nome de família", por ser bastardo, por ser exposto ou por ser extremamente pobre. 
ortanto, significativo que as leis portuguesa e brasileira concedam uma tão grande liberdade na atribuição e escolha de sobrenomes e que permitam com mais facilidade a alteração dos sobrenomes que dos nomes próprios. A lei permite a atribuição de sobrenomes herdados por linha feminina ou masculina ou ainda herdados de pais, de avós ou de bisavós, concedendo assim uma considerável margem de manipulação antroponímica (cf. Pina Cabral e Viegas 2007). Ocorre aí uma espécie de correcção retrospectiva. Apesar de existir uma grande liberdade quanto à transmissão de sobrenomes (matrilaterais ou patrilaterais), as "famílias" são identificadas por sobrenomes que se presume, retrospectivamente, terem sido herdados sempre segundo as regras preferenciais do Registo Civil, que concedem prioridade à descendência patrilateral. Nas lápides dos cemitérios, lá encontramos "Família Correia Antunes" ou "Família de José Maria Correia Antunes", ficando em aberto saber qual a história familiar que levou José Maria, a sua viúva e os seus filhos ou sobrinhos a usar o sobrenome Correia Antunes como definidor da família (se era o nome do pai dele ou da mãe dele, do avô paterno ou materno, se Correia era da mãe e Antunes do pai, etc.).

Existe todo um folclore relativo à suposta origem (familiar e não etimológica) dos sobrenomes. No Baixo Sul da Bahia, os sobrenomes dados a escravos catequizados são tão frequentes que funcionam como uma marca de "indistinção". Assim se passa com os "dos Santos" ou os "de Jesus" em Valença, onde cerca de $60 \%$ da população estudantil tem um ou ambos estes sobrenomes no seu nome. Mais uma vez a conotação de sobrenomes com propriedade e condição de classe é marcada: uma jovem explicava-me que "Ser Santos é atestado de pobreza!" As pessoas de Valença, portanto, num esforço de se diferenciarem, procuram manipular a atribuição de sobrenomes no sentido de passar aos filhos sobrenomes mais diferenciantes (cf. Pina Cabral 2007b).

A elaboração deste tipo de conotações pode chegar a ser bastante complexa. Na mesma cidade, uma jovem jornalista explicava-me que desejava deslocar-se a África para procurar "suas raízes". Perguntei-lhe porque é que ela achava que eram essas as suas raízes, já que a sua cor de pele ("parda", como se diz no Brasil) sugeria que teria tido antepassados também de outras raças. Respondeu-me que tinha certeza da sua origem africana porque se chamava Barreto, "nome de português." Ora, como a sua pele é escura, era de presumir que o nome teria pertencido a um escravo que o recebera do seu dono. Concluía, portanto, que teria que procurar "as suas raízes" em África.

Por relação a outras tradições antroponímicas, uma das marcas da lusofonia, onde quer que esta se tenha inscrito, é uma tendência para uma baixa criatividade em ambos os tipos de nomes. Em princípio, a lista de sobrenomes é finita. Já quanto aos nomes próprios, há contextos de maior ou menor criatividade. $\mathrm{O}$ exemplo mais extremo de conservadorismo antroponímico que conheço é, porventura, o das famílias da alta sociedade lisboeta estudadas por Antónia Pedroso de Lima (2007). Há, porém, exemplos de maior criatividade, como o caso por mim estudado de Valença, no Baixo Sul da Bahia. Mesmo aí, porém, a investigação revelou que poucos são os nomes genuinamente inventados; isto é, sem qualquer conhecimento prévio pela pessoa que nomeia (2007b). Existem fortes pressões em todos os contextos lusófonos no sentido de reduzir a inventividade, muito especialmente dos nomes próprios.

20 Enquanto há nomes próprios que se tornam sobrenomes, a ocorrência inversa é desconhecida - a lei portuguesa e brasileira impedem-na e o costume desencoraja-a. 0 sistema de atribuição também é assimétrico, já que, num primeiro momento, há uma aparente liberdade na escolha do nome próprio e um relativo constrangimento na 
escolha do sobrenome. As pessoas escolhem os nomes próprios dos filhos segundo lógicas que se apresentam como sendo particularísticas e familiares: era o nome da avó, era o nome da madrinha, era o nome do chefe do pai, era o nome do padre que ajudou a família, etc. Alternativamente, procuram nomes "bonitos", "chiques", "modernos", "que dêem sorte" - em suma, cujas conotações valorizem a criança. Este tipo de lógica varia de contexto para contexto, consoante as práticas de associação que estruturam a vida familiar. Contudo, a lógica agregada destes actos de atribuição conforma tendências de características só parcialmente cognoscíveis pelos agentes. Existem tipicamente modas e os nomes vêm em surtos, o que põe em causa a aparência inicial de liberdade na atribuição de nomes próprios versus o constrangimento nos sobrenomes. Em suma, existem de facto liberdade e constrangimento na atribuição de ambos os nomes, mas de modos distintos. No caso dos nomes próprios, a liberdade de natureza lexical é constrangida por considerações morais e de decoro; no caso dos sobrenomes, a escolha recai sobre um lista finita de sobrenomes familiares mas é possível escolher entre estes.

21 Até há pouco tempo, a atribuição de nomes estava muito ligada ao culto católico dos santos e havia regras de transmissão de nomes (entre padrinhos e afilhados, entre avós e netos, de pai para filho mais velho). Estas tendências alteraram-se com o acesso à sociedade de consumo, aos mass media e com o maior laicismo contemporâneo, mas não é tanto o sistema de atribuição de nomes que muda como a origem das referências escolhidas. No caso que é explorado pelo seriado carioca Cidade dos Homens uma mãe chama ao seu filho Uólace e a outra João Pedro. Estão ambas a usar o mesmo sistema de nomeação. Estão ambas sujeitas à moda e ambas tentam aumentar o valor do seu filho pela atribuição de um nome "bonito". Só divergem nas conotações que escolhem conotações que remetem para o nível de escolaridade e que, portanto, deixam Uólace a perder em certos contextos, que não noutros. Fica a perder não porque a sua mãe o desejasse, muito pelo contrário, mas porque a hegemonia simbólica existente na sociedade abrangente funciona de tal forma que o seu nome em vez de o promover o subalterniza.

Em alguns contextos, como no Portugal contemporâneo, o conservadorismo inconsciente na atribuição de nomes próprios é de tal forma marcado que chega a causar desconforto aos nomeados que, numa turma de escola, podem ter $15 \%$ dos colegas com o mesmo nome próprio que eles. Até nos casos de maior liberdade antroponímica, como no Baixo Sul da Bahia, esses surtos são visíveis, apesar de mais atenuados: não só através da repetição de alguns nomes (p. ex., entre os alunos do secundário de Valença, Paulo Henrique) como ainda do recurso a estilos específicos de constituição de nomes (p. ex., desvalorizar os nomes de santos católicos, contrariamente a gerações anteriores).

O que este processo de convergência estatística na atribuição de nomes próprios significa é que as escolhas são identificáveis de forma vaga com a pertença social de quem as fez. Assim, por exemplo, ser chamado Maria qualquer-coisa, em Valença hoje é um forte estigma e significa que se veio da tão desprezada "roça" (a zona rural). Já na minha geração, por exemplo, na burguesia do Porto, ser chamado Adérito, Aníbal ou Euclides era decididamente um empecilho à promoção de classe. Nos contextos lusófonos, portanto, a escolha de nome está associada a culturas locais e corresponde a imagens vagamente partilhadas do estilo de vida desejável e do tipo de personalidade 
desejada para os filhos. Por isso não reflecte os desejos e valores dominantes de forma directa; mas antes estatisticamente, como uma moda.

Em certas populações ameríndias, as pessoas possuem um património antroponímico que protegem, transmitem, aumentam ou perdem; os nomes pessoais condensam valor e são objecto de propriedade (cf. Lopes da Silva 1986). Da mesma forma, os juristas portugueses constituíram o curioso conceito de "património onomástico nacional" (Pimenta 1986) - como se os nomes próprios em português constituíssem um valor de tipo cultural, parecido com a arte ou a arquitectura pública. Este conceito está por trás da noção quase universalmente consensual de que é colectivamente errado permitir às pessoas que atribuam nomes novos aos seus filhos - um crime parecido com montar janelas de alumínio brilhante num edifício medieval. o que está em causa aqui é um curioso processo de acumulação de actos de mais-valia, que acaba por conferir uma aparência de valor estável. Tal como no caso do objecto artístico, esse valor nunca é apercebido como unicamente estético e assume sempre um valor de consumo.

Ora é isso mesmo que se passa com as tais listas dos nomes próprios permitidos e proibidos, que a lei portuguesa promove, os juristas validam, os linguistas gerem e os burocratas impõem; todos eles imbuídos de um enorme sentimento de zelo moral, que sempre me deixou perplexo. ${ }^{5}$ Tendo tido ocasião por várias vezes de acompanhar e apoiar o registo em Portugal de cidadãos nacionais nascidos no estrangeiro com nome estrangeiro, verifiquei que (a) não há qualquer interesse controlante por parte dos burocratas nos sobrenomes estrangeiros (pelo contrário, considera-se automaticamente que estes "ficam bem" e valorizam até o parque ${ }^{6}$ onomástico nacional) e (b) há um prurido moral exacerbado por parte dos burocratas no policiamento dos nomes próprios. Não é esta a ocasião para descrever os numerosos casos de hipercorrecção etnocêntrica (quando não mesmo racista) a que tive a ocasião envergonhada de assistir em cartórios do Registo Civil em Lisboa. $O$ argumento que estas pessoas ferozmente esgrimem para impedir que esses "estrangeiros" (que, no caso, eram cidadãos nacionais incontestavelmente) tenham o nome próprio que querem ter é absolutamente espúrio. Trata-se, sustentam eles com enorme fúria, de um empenho legítimo em assegurar a correcta e legal "identificação" da pessoa. Curiosamente, esta sua sanha burocrática nunca versa sobre sobrenomes e, pelo contrário, as regras que eles protegem com tanto empenho no referente aos nomes próprios são depois tratadas de forma altamente inconsistente no referente aos sobrenomes (sendo sistematicamente permissivos nos abusos da polionomásia). Mais uma vez, aqui se revela a assimetria binómica entre nomes próprios e sobrenomes na tradição lusófona.

Quando a lei brasileira insiste que o nome da pessoa é imutável, ela está a referir-se ao nome próprio, porque nos usos dos sobrenomes existe uma grande opcionalidade. No casamento, as mulheres podem acumular novos sobrenomes ou alterar os que tinham. A maioria das pessoas tem entre dois e quatro sobrenomes e está livre de se apresentar por uma qualquer combinação destes. Este, por exemplo, era um traço do sistema antroponímico lusófono que chocava os chineses de Macau, para quem o sobrenome patronímico e não o nome próprio é que é sempre certo e imutável.

Ana Maria Machado chama atenção para a importância da polionomásia na lusofonia. Quer dizer, o facto de os sujeitos lusófonos terem caracteristicamente "nomes longos", o que lhes permite uma grande opcionalidade no recorte e uso tanto de sobrenomes como de nomes próprios - com a consequente possibilidade de gerir os ecos 
nominativos. Trata-se de uma forma caracteristicamente burguesa de usar o nome, constituindo nomes públicos que são soluções de continuidade entre o nome formal e o pseudónimo e que se prolongam domesticamente em hipocorísticos. A lei portuguesa e brasileira contempla regras sumptuárias, no sentido de restringir a proliferação de nomes. No entanto, basta apreciar uma qualquer lista de pessoas da elite portuguesa (por exemplo, os subscritores de um livro sobre a nobreza no século XIX) para ver que estas regras são sistematicamente contornadas. É frequente encontrar pessoas com sete e oito nomes (o que é explicitamente proibido pela lei). A vontade das pessoas de dar aos seus filhos muitos nomes (nomes próprios e sobrenomes) como forma de distinção sobrepõe-se à lei.

Segundo a autora, "a polionomásia, no plano linguístico, encontra correspondência e simetria na plurissignificância enquanto recurso estrutural" (1991: 139). O nome longo adquire, assim, um sentido estrutural na medida em que permite uma forma de exploração que joga com contextos de uso diferentes (onde diferentes partes do nome são usadas), diferentes referências familiares (remetendo para diferentes "famílias" sinalizadas por sobrenomes) e diferentes ecos nominativos (um jogo de conotações). 0 nome, assim, explora as possibilidades abertas à pessoa.

Em suma, o sistema antroponímico joga com a oposição pessoa/família através do binómio assimétrico nome próprio/sobrenome. A assimetria conjuga-se por meio da oposição entre liberdade versus constrangimento na atribuição e a oposição entre ser versus ter no uso. À essencialidade do nome próprio opõe-se a natureza adjectival e agregada do sobrenome que possui, portanto, menos peso ontológico. Quero dizer, estas práticas nominativas encontram-se estruturadas de tal forma que tendem silenciosamente a encorajar uma visão do mundo que concede essencialidade à pessoa e, correlativamente, reduz a essencialidade das identidades suprapessoais. $O$ aspecto central deste princípio, pois, é que há um pendor individualista inscrito nestas práticas nominativas. $^{7}$

Mais ainda, a partir da Época Moderna (século XVI e seguintes), o surgimento de um aparelho legal afecta a forma como os nomes são usados. Ora, esse aparelho legal atribui uma essencialidade absoluta à pessoa física, que leva a que as outras formas de identidade social suprapessoais sejam legalmente classificadas como metáforas da pessoa física (cf. Pina Cabral 1991: 119-124). Nomes de casa ou nomes de linhagem são subalternizados e não é atribuída às casas ou às linhagens a mesma relevância legal que é atribuída às pessoas físicas - ao ponto de a sociedade acabar por ser formulada como um agregado de "cidadãos", que são e só podem ser pessoas físicas.

31 Como nome da alma, o nome próprio remete para uma essência que, em termos teológicos cristãos, sobreviverá para todo o sempre. As famílias são, assim, apresentadas como agregados de pessoas, como entidades colectivas. O sobrenome agrega-se ao nome completo por adição - essa é a relação formal que estrutura este binómio. Por isso até, antes da vulgarização do Registo Civil, muitas pessoas - e nomeadamente as mulheres - só tinham um nome próprio, não chegando a receber nunca um sobrenome.

\section{O nome verdadeiro}

Uma segunda recorrência estruturante de todo o sistema antroponímico lusófono é a existência de uma diferença de natureza ontológica entre o "nome mesmo" e as outras 
formas de chamar. Esta diferença estabelece uma oposição entre o nome que o aparelho burocrático valida (o Estado ou a Igreja) e todas as outras formas de nomeação a que a pessoa possa estar sujeita através da sua vida. Os nomes familiares (hipocorísticos), os nomes comunitários (alcunhas, "apelidos" no Brasil) e os pseudónimos são, porventura, os mais importantes de entre estes, mas a lista não se esgota aí. Quando inquirimos pessoas lusófonas sobre os seus nomes, surgem invariavelmente formulações do género, "o meu nome de verdade", "o meu nome certo", "o meu nome real", “ o meu nome de facto", "chamam-me x, mas o meu verdadeiro nome é y".

Por vezes, a diferença é descrita sob a aparência de nome "oficial", "formal", "nome de registo" - como se o que estivesse em causa fosse uma relação entre um aparelho burocrático, mais ou menos distante, e uma vida informal, onde a nominação poderia ser muito mais livre. Curiosamente, porém, maior liberdade não parece corresponder a maior veracidade. Nos muitos casos que tenho inquirido por esse mundo fora, as pessoas nunca negaram a maior "veracidade" ou "correcção" do nome oficial. Este último é sempre tido como mais representativo de quem eles realmente são ou devem ser do que o nome informal. Mesmo em contextos de iliteracia dominante, em que as pessoas chegam a estar incertas sobre os seus próprios nomes oficiais, estes têm sempre uma legitimidade ligada ao poder simbólico do Estado (e, anteriormente à década de 1930, à Igreja) que se afirma face às práticas onomásticas comunitárias. Por exemplo, no Baixo Sul da Bahia, tanto quanto no sul de Moçambique ou no Alto Minho camponês, as pessoas que não têm um nome oficial, que não o sabem escrever ou cujo nome oficial é de todo irrelevante para a sua participação social, são diminuídas por isso; não só face aos outros, mas também face a si mesmas.

o nome que distingue é o nome oficial. Por isso, quando a alcunha ou o nome artístico se tornam publicamente muito conhecidos é frequente as pessoas tentarem adicionálos a este. Só rarissimamente, porém, tentam substituí-los ao nome próprio anterior. Os tribunais, aliás, são muito renitentes em permiti-lo. Os nomes de origem informal a adicionar, mesmo quando são hipocorísticos derivados do nome próprio (como Lula para Luís), são adicionados com o estatuto de sobrenome. No caso do Presidente da República brasileiro, por exemplo, o sobrenome que os filhos herdaram passou a ser Lula da Silva. Aqui a maior essencialidade do nome próprio face ao sobrenome joga um papel relevante.

35 Há ainda que insistir que a mudança oficial do nome não é algo que uma pessoa faça de alma leve. Isto muda de contexto para contexto, mas as implicações são sempre fortíssimas. Estou, claro está, a falar do nome próprio, já que a alteração do sobrenome, a adição de mais sobrenomes ou o acto de retirar alguns não causa problemas e o sistema jurídico facilita esse tipo de alterações. Conheço casos no Baixo Sul da Bahia de mudança legal de nome no sentido de adicionar ou retirar uma partícula "de/dos" ou de retirar ou adicionar um ou mais sobrenomes.

36 Normalmente, quando questionadas, as pessoas afirmam "gostar" do seu nome próprio. Pude observar, porém, que existe sempre uma percentagem (minoritária mas significativa) da população que afirma "não gostar". As pessoas não protestam da mesma forma contra o sobrenome, até porque geralmente têm mais que um e podem silenciar aqueles de que não gostam ou adicionar os que sentem que lhes faltam. Tais pessoas têm narrativas exegéticas elaboradas nas quais o nome próprio de que não gostam é contrastado com as qualidades que atribuem a si mesmas. Por exemplo, uma vez encontrei uma senhora numa cidade de província brasileira que, tendo sabido que 
eu estava a "estudar nomes," manifestou incómodo com isso, acusando-me de vir ao Brasil estudar um tema que diminuía os brasileiros. Após eu ter mostrado que assim não era, a senhora passou a explicar porque não gostava do seu nome: Adryana. Afinal, era o "y" que a incomodava, já que considerava que essa redacção era errada, demonstrando falta de sofisticação da parte do seu pai. Ao explicar-me o facto, ela mostrava que, contrariamente aos seus pais e aos funcionários do cartório, ela era uma pessoa "culta", "sofisticada". o "y" mal posto, afinal, não era tanto uma ocasião para se sentir diminuída (até porque teria sido fácil alterar a grafia) como uma ocasião de se afirmar face a um académico estrangeiro e mais velho, que poderia talvez, secretamente, por trás da fachada de simpatia, estar a pensar que ela era de alguma forma menos sofisticada. Em suma, ao chamarem a atenção para o "erro" de nomeação, as pessoas estão, por assim dizer, a reabrir o nome face a uma associação que sentem ser excessivamente forte ou perturbante - estão a reconstituir os ecos nominativos do seu nome.

o que me surpreende mais nestes casos é que são muito raras as pessoas "que não gostam do seu nome" que realizam um esforço efectivo para o mudar. Não só a lei é muito arredia a isso, como as pessoas sentem (e o pessoal jurídico exprime-o francamente) que é errado e até mesmo perigoso mudar de nome próprio. No Baixo Sul da Bahia, foram-me relatadas histórias familiares trágicas de pessoas que, tendo finalmente mudado o nome próprio que toda a vida os tinha incomodado, perderam irremediavelmente a relação de proximidade que anteriormente tinham com os filhos. Independentemente da sua real ocorrência, o impacto lógico destas narrativas é que a mudança do nome próprio que foi atribuído pelos pais ou padrinhos na infância envolve uma espécie de alteração da identidade essencial da pessoa.

Neste jogo de gostar ou não voltamos a confrontar, portanto, o tema da reminiscência. o que está em causa é uma essencialização da pessoa através de um processo de gestão de citações de nomes. Isto, por sua vez, é realizado através de um esquema de exploração narrativa. Por isso, o processo em geral é abordado com entusiasmo. Quero dizer, sempre me surpreendeu a prontidão com que as pessoas "que não gostam do seu nome" estão dispostas a explicar porque não gostam; já que, sendo o nome uma coisa tão importante para a identidade pessoal da pessoa, elas poderiam estar a identificar um qualquer estigma. De facto, tal não se passa, porque a ilação principal está errada: a identidade não é algo de fixo e de interior, é algo de exterior à pessoa. Visto como reminiscência, o nome de que não se gosta acaba por funcionar como uma ocasião para a construção identitária. Por isso a sua exploração valida e não diminui. Por isso é que as pessoas que encontrei no Brasil que, de facto, têm nomes que poderiam causar riso não parecem lidar nada mal com a situação e, contrariamente ao que a opinião consensual dos entrevistados toma como seguro, acabam por usar até o seu "nome diferente" como um asset comunicacional.

Esta noção de que o "nome ridículo" deve ser evitado a todo o custo prende--se com a associação entre o nome próprio e a honra da pessoa (o seu valor e prestígio social, a sua "verdade interior"). Assim, uma pessoa que por qualquer "erro" ou "crime" dos seus pais ou do oficial do registo tenha um nome que reduza a sua honra pode solicitar a mudança desse nome e, na verdade, frequentemente essa alteração é permitida. A questão da honra pessoal (no sentido geral de valor social da pessoa) é essencial para este debate. O nome informal é um nome mais igualitário e, ao mesmo tempo, subalternizante. Quanto mais "honrada" a pessoa é, mais o seu nome oficial se torna 
relevante. E aqui não falamos necessariamente de sobrenomes, já que, por exemplo, os reis não tinham propriamente sobrenome. No caso dos políticos brasileiros que, propositadamente, se apresentam através de nomes informais, o que está em causa é precisamente uma espécie de negócio político em que um homem de poder, através da aceitação de uma alcunha mais ou menos desvalorizadora ("Lula", "Bóia-Fria", "Zé Pretinho", etc.) pretende rebaixar-se por forma a apresentar-se como igual ao votante. Mesmo assim, algumas das alcunhas políticas mais famosas no Brasil retêm um elemento de distanciamento formal. ${ }^{8}$

Os nomes formais não são opcionais nem se referem a quem a pessoa se tornou durante a vida, mas sim a quem ela é à partida. "O nome pessoal é imutável", diz a lei brasileira. Contrariamente a outras tradições antroponímicas, nos meios lusófonos, a pessoa não pode mudar de nome quando muda de estatuto, nem lhe são adicionados no decorrer da vida novos nomes, ligados a ocorrências importantes no seu percurso pessoal. 0 nome está ligado ao baptismo (ou ao seu herdeiro laico - o registo civil) e é atribuído no momento em que a criança é fisicamente consolidada, uns dias após o parto. ${ }^{9}$ No século XIX, o registo civil do nome era consequência do baptismo, hoje é condição para o baptismo. Existe, na verdade, um estatuto de paralelismo histórico entre os dois actos (cujo passado longínquo é comum, nas decisões do Concílio de Trento). Assim, as implicações teológicas do significado atribuído aos nomes próprios - que ligam o nome com a alma - não são simplesmente descartáveis só porque ocorreu uma laicização e pluralização religiosa das sociedades lusófonas.

41 Existem dois tipos de excepção a referenciar à imutabilidade do nome próprio: (i) o caso das pessoas que entram em ordens religiosas e "deixam a família" e, num certo sentido, "renascem" (chegando por vezes, mas raramente, a mudar até o nome próprio) e (ii) o caso das pessoas que "têm nomes ridículos". ${ }^{10}$ No primeiro caso, o que está em causa é a desobrigação da pessoa por relação à dominação familiar; no segundo, está em causa o desejo de preservar o valor intrínseco (sagrado) da pessoa. À parte estes dois casos, a mudança do nome próprio atribuído na infância é altamente dificultada pela lei. Contrariamente ao que é convicção de todos com quem temos falado sobre o assunto (aliás, os tratados legais afirmam-no como facto indiscutível), não é verdade que exista uma qualquer razão imperativa de ordem burocrática que torne impraticável a mudança de nome. Nos Estados Unidos da América ou na China - países altamente eficientes de um ponto de vista da gestão burocrática das pessoas - é fácil mudar de nome próprio e não é por isso que surgem problemas de gestão burocrática. 0 que está em causa é que, numa tradição antroponímica como a lusófona, onde o nome próprio é profundamente essencializante, a sua estabilidade apresenta-se como garante da inserção social da pessoa. ${ }^{11}$

O nome lusófono, aliás, é tão estável quanto público. A contribuição de Alcida Rita Ramos para este volume chama a nossa atenção para tal facto, desnaturalizando-o. A questão não é estritamente de natureza legal, já que se considera que uma pessoa tem a obrigação de informar os outros sobre o seu "verdadeiro nome" e é mesmo considerado ilegítimo recusar essa peça de informação. Uma pessoa que use um pseudónimo terá que o fazer com explicitude ou em contextos determinados, caso contrário isso será considerado um ludíbrio por parte de quem com ela comunica. As atitudes de etnocentrismo que os portugueses demonstravam nos anos $90 \mathrm{em}$ Macau face à facilidade com que os chineses de classe média adoptavam e cambiavam os seus nomes próprios (tratando-os quase como os portugueses tratavam alcunhas) foram já 
referenciadas por mim próprio num texto sobre o assunto (cf. Pina Cabral 2003: cap. VII).

O nome lusófono é público na medida em que não é para ser escondido. Note-se, por conseguinte, que a possibilidade de anonimato que assim resulta não é um predicament da condição humana. É, outrossim, resultado do facto de a pessoa, caso interpelada, ter a obrigação de referir o seu nome (cf. Frois 2007). Esta concepção, claro está, prende-se com a ligação do nome ao aparelho burocrático (tanto face ao Estado como à Igreja) mas ultrapassa-a largamente. Senão, vejamos que uma das diferenças que existem entre as práticas nominativas lusófonas mais hegemónicas e algumas das suas variantes crioulas se prendem precisamente com esta característica. Tal é exemplificado claramente pelos casos estudados por Paulo Jorge Valverde em São Tomé (2000: 142-156), em que as pessoas sentiam que o seu "nome de saída" (nome oficial) tinha tanto poder evocativo que era preferível que outros não lidassem com ele, por forma a evitar que fosse usado contra eles próprios por meios mágicos.

Este recurso aos nomes para praticar actos mágicos sobre a pessoa não se limita de forma alguma a este contexto, podendo ser encontrado em praticamente todos os contextos lusófonos, históricos e actuais. O que está em causa no exemplo acima referido, assim como em alguns casos de relutância em transmitir o nome por virtude de medos mágicos que eu próprio encontrei no Baixo Sul da Bahia, é a confrontação da essencialidade do nome próprio com a sua publicidade; a primeira torna-o intrínseco à pessoa, a segunda torna-o público. Cria-se uma contradição que ameaça as pessoas no seu mais íntimo e as obriga a recorrer a toda uma série de processos de mediação simbólica essencialmente ambíguos. O exemplo que Paulo Jorge Valverde cita da entrevista com um homem que tem relutância em dar-lhe o seu "nome de saída" mas que acaba por o declarar indirectamente, é bem característico do tipo de equívoco que se forma quando estes dois aspectos se entrechocam. Existe ambiguidade, porque o próprio conceito são-tomense de "nome de saída" sugere que o que está em causa é um nome que, contrariamente a outros mais quotidianos ou mais íntimos, serve para confrontar o mundo exterior (lá fora) - é público.

Esta natureza não-anónima dos nomes lusófonos torna-se bem patente quando se comparam as formas de utilização dos nomes de pessoa com as que são vigentes em populações que não se inserem dentro desta longue durée que temos vindo a identificar. Por exemplo, David Maybury-Lewis conta sobre os Xavante do Brasil:

uma das minhas mais árduas tarefas ao tentar reunir informação genealógica foi a de identificar os indivíduos nos meus mapas. Eles eram muito tímidos na revelação dos seus nomes; a resposta mais comum a um pedido directo dessa informação por parte de um homem ou de uma mulher era "eu não tenho nome". Contudo, por vezes, sentava-me longamente com os membros de uma família e, aos poucos, acabava por obter os nomes de quase todos eles, com a excepção de uma ou duas mulheres que sustentavam ainda assim que não tinham nome, apesar das incitações exasperadas dos seus maridos para que não fossem tontas. (1974: 234)

Esta passagem é fascinante em muitos aspectos, particularmente porque o problema com que Maybury-Lewis se confronta é, como ele diz, "identificar os indivíduos" - quer dizer, ele estava a usar nomes de pessoas de formas que violentavam a forma como as pessoas locais eram construídas, porque a sua prática genealógica ${ }^{12}$ presumia uma utilização de um tipo de laço entre pessoa física e nome que não se adequava às práticas dos Xavante. Ele próprio nos assinala isso, quando afirma: "Dir-se-ia [...] que os nomes Xavante não têm, ou só têm parcialmente, a finalidade de identificar indivíduos 
particulares. Nem proporcionam um esquema classificatório independente." (idem: 234) Levanta, então, a possibilidade de os nomes terem a ver com cargos - seguindo na linha do argumento de Mauss. ${ }^{13}$

Não sei se a citação é consciente ou se é meramente o efeito do conhecimento geral que o autor tem da teoria antropológica: "Levanta-se a [...] possibilidade dos nomes Xavante estarem ligados a estatutos e a sua atribuição implicar a sucessão ao estatuto que transportam. Esta função seria parecida, mas não idêntica, com a de um sistema de nomes como instrumentos de classificação. Não consegui encontrar evidência que corroborasse esta possibilidade." (idem: 235) Mais uma vez, portanto, a resposta do autor parece ser ambígua, limitando-se a sugerir implicitamente o etnocentrismo dos pressupostos da tradição teórica durkheimiana que, desde os primeiros textos de Mauss sobre o assunto, tendem a identificar a pessoa como unidade social elementar através de uma associação entre papel social, máscara e pessoa. ${ }^{14}$

A passagem é ainda interessante pela referência velada ao pressuposto lévi--straussiano de que os nomes pessoais seriam sistemas de classificação. No mesmo ano em que saiu o livro de Maybury-Lewis (1974), Lévi-Strauss organizava em Paris um simpósio em que a questão da nomeação era tratada sob esse ângulo e para o qual Martine Ségalen e outras etnógrafas europeístas escreveram textos que se tornaram famosos (cf. LéviStrauss 1977; Pina Cabral e Viegas 2007). Sem recusar o valor heurístico desses esforços, parece urgente ultrapassar a visão que trata as formas de nomeação implicitamente como sistemas classificatórios e abordar a nomeação pessoal no âmbito do jogo de empatia e agonismo relacional característico das práticas sociais. Sem negar a sistematicidade implícita neste tipo de formas nominativas, reduzi-las ao aspecto semiótico da representação seria retirar-lhes toda a força implícita na sua condição de práticas constituintes de agentes e de contextos de dominação.

Voltando, portanto, ao caso em discussão, o exemplo Xavante é bem útil para mostrar que o conceito de "anonimato" não se adequa de todo a essa sociedade, onde não se aplica a própria noção de que haja um espaço "público" que tem poder para obrigar a pessoa a declarar-se perante ele e face ao qual, por conseguinte, a pessoa se protege manipulando o anonimato - noção essa profundamente associada a sociedades de Estado/Igreja. O "sussurrar dos nomes" de que nos fala Alcida Rita Ramos entre os Sanumá, a tal "timidez" que chega a raiar a "tontaria" entre os Xavante (e, em especial, et pour cause, as mulheres) mostra que não é só a constituição e atribuição de nomes lusófonos que transporta implicações sociais, mas também as suas expectativas de uso.

Estes exemplos ameríndios revelam que a forma como os nomes podem ou devem "ser ditos" presume características sob a constituição dos sujeitos que os usam, contrastando com a tradição lusófona (cf. Lopes da Silva 1986). Da mesma forma, do outro lado do mundo, onde as práticas de nomeação lusófonas se confrontam com outros universos civilizacionais - em Timor - algo de muito semelhante é relatado pela etnógrafa Elizabeth Traube: "Os Mambai evitam usar nomes pessoais, e eu era conhecida durante toda a minha estadia como a 'Menina', uma apelação à qual acabei por me habituar a responder como se fosse o meu próprio nome." (1986: xiii, itálico meu) ${ }^{15}$

51 Voltando aos contextos lusófonos, se tentarmos dar ordem à categoria residual dos nomes que não são o nome formal, descobrimos que temos enorme dificuldade em listar todos os tipos possíveis: alcunhas, apelidos (bras.), nominhos, nomes de escárnio, diminutivos, nomes de guerra, pseudónimos... a lista não parece ter fim. A característica mais geral desta enorme e variada família de práticas nominativas é 
negativa: definem-se porque não são tão "verdadeiras", tão "certas", tão "completas" quanto o nome oficial e, mais ainda, na frase recorrente dos entrevistados, por não serem "escritas". "Ser escrito" significa ser mais verdadeiro - verifica-se esta associação em praticamente todos os contextos de lusofonia. As pessoas que não reconhecem ou não são habitualmente chamadas pelo seu nome oficial são diminuídas por isso. "Não ter nome escrito" ou "não ser conhecido pelo seu nome" é, num certo sentido, não ter nome; uma marca indelével de subalternidade.

52 Todos temos, porém, outros nomes para além do oficial. Estes mudam de facto durante a vida dos indivíduos e uma pessoa reconhece sempre mais que um. São geralmente nomes localizados, que se prendem a uma actividade ou a uma relação qualquer e têm implicações de familiaridade, igualitarismo ou subalternidade. Um mecânico de Valença a quem perguntei o nome, por exemplo, respondeu "Meu nome é Sarará." ${ }^{16}$ Ao que eu perguntei surpreso, "Mas isso é seu nome mesmo?" E ele fechou: "Não, nome mesmo não é. É nome de garagem."

Quando comparada com o nome oficial, esta família de práticas antroponímicas é caracterizada por volatilidade, plasticidade e liberdade atributiva. Em situações de complexidade linguística, onde as pessoas têm nomes que remetem para sistemas antroponímicos distintos (Macau, Timor, Moçambique, ameríndios brasileiros) surgem regras informais para gerir a conjugação ou alternância dos nomes da mesma pessoa nas distintas línguas. Normalmente, os nomes próprios são os primeiros a mudarem para nomes lusófonos, por causa das suas implicações religiosas; os nomes aliógenos que são interpretados como sobrenome tendem a sobreviver durante mais tempo.

o nome oficial lusófono é mais verdadeiro, mais representativo da pessoa naquilo que ela tem de mais nobre e essencial - por isso é inalterável depois de atribuído no momento do baptismo ou do registo civil e prolonga-se para além da morte. Não há nomes funerários nas tradições de origem ibérica, nem tal seria imaginável. 0 nome próprio é o nome da alma e esta, uma vez criada, continua para todo o sempre após a morte. A ligação do nome próprio com o conceito cristão de alma não só é historicamente determinante como está perfeitamente activa na actualidade, mesmo por parte de populações que não transportam essa preteridade teológica ou que a rejeitaram largamente a favor de um laicismo modernista.

Sumariando, mais uma vez nos encontramos perante um binómio assimétrico que se formula através de uma escala de maior e menor verdade: neste caso, entre nome oficial e outros nomes. Atribui-se solidez ontológica relativa a diferentes tipos de nome. Não é que esses outros nomes deixem de existir, no sentido de não serem menos usados como forma de identificação e chamamento. Outrossim, a sua existência é concebida como mais ténue; como se, existindo, existissem menos. Quando perguntamos se uma ou outra instância particular de um nome não-oficial qualifica menos bem a pessoa, a resposta é negativa. $O$ problema é que é difícil ou quase impossível fazer a pergunta no geral, já que, como seria de esperar, não existe em termos émicos uma categoria que abranja todos esses tipos de outros nomes.

Trata-se de um binómio assimétrico, mas constituído de forma distinta do anteriormente considerado. Enquanto a oposição entre nome próprio e sobrenome funciona por adição, neste caso a oposição realiza-se por meio de uma subtracção. Isto é, no caso anterior, a assimetria opunha algo de singular e essencial (a pessoa) a algo que é visto como colectivo e, portanto, plural (a família). Neste caso, a subtraç̧ão não funciona no sentido de apagar entidades (outros tipos de nome) mas no sentido de as 
reduzir, de as diminuir, de as minimizar. Trata-se, pois, de um processo de silenciamento hegemónico realizado através de um complexo aparelho ideológico e administrativo (originalmente religioso e, mais tarde, religioso cum estatal). Esse silenciamento retira solidez às formas de reminiscência da pessoa que não são corroboradas pelo aparelho burocrático (religioso e estatal) mas não as proíbe ou destrói. Fá-lo para os outros nomes através do bloqueamento da efectivação e legitimação dos três processos constituintes da reminiscência: a essencialização, a citação e a exploração.

Por este meio, o que é mais público (quer dizer, os nomes efectivamente usados para convocar e identificar pessoas) torna-se privado; o que é audível (os nomes por meio dos quais as pessoas mais vezes se chamam umas às outras) torna-se menos verdadeiro. Pelo contrário, o nome oficial - aquele que muitas pessoas mal conhecem, que a maior parte de nós amputa quando nos referimos a nós próprios e pelo qual nunca somos chamados - torna-se a "verdade"; torna-se o meio por excelência de reminiscência da pessoa prendendo-a, assim, irremediavelmente às três instâncias de construção colectiva que o nome valida: família, Estado/Igreja e género - questão que abordarei de seguida.

\section{O nome sexuado}

A terceira grande área de recorrência antroponímica lusófona é a diferenciação de género. A questão tem de ser abordada separadamente para o nome próprio e o sobrenome. As suas implicações foram já largamente explicitadas no livro Nomes: Género, Etnicidade e Família (Pina Cabral e Viegas 2007), pelo que serei breve na sua discussão. No que se relaciona com os sobrenomes, a evolução legal que Nuno Gonçalo Monteiro identifica (neste volume) - e que ocorre em Portugal e no Brasil entre as décadas finais do século XIX e os anos 1930 - só altera em alguns aspectos secundários as implicações do sistema. As práticas nominativas básicas, que se encontram vigentes desde as alterações que ocorreram no início da Época Moderna ( $v d$. Robert Rowland neste volume), presumem uma forma de família que assenta sobre o casal monogâmico, onde não existem linhagens patrilineares nem matrilineares (cf. Pina Cabral 1991: 143-159). Assim, quando têm sobrenome e este é relevante, as mulheres sempre puderam passá-lo aos seus descendentes (tanto o seu sobrenome matrilateral como o patrilateral). Até à década de 1930, a passagem de sobrenomes era relativamente solta mesmo no interior de uma mesma família conjugal, mas sempre foi presumido que a principal inserção familiar de uma pessoa (e, portanto, também a antroponímica) fosse a patrilateral. Essa presunção, porém, como sabemos do material etnográfico estudado, não era sempre igualmente válida em todas as regiões de Portugal.

Por oposição aos sistemas transpirenaicos, as práticas antroponímicas ibéricas permitem uma bilateralidade na herança de sobrenomes e uma margem considerável de manobra na transmissão, de tal forma que, caso desejado, é simples recorrer ao sobrenome matrilateral. Conjugadas, estas duas características associam-se à discussão que fizemos anteriormente sobre a menor essencialidade do sobrenome face ao nome próprio. Assim, nos sistemas lusófonos, a passagem dos sobrenomes tem algo de enganador porque se presume (a) que ocorre de formas sistemáticas, quando tal não se passa necessariamente, e (b) que existe um patriarcalismo rígido, quando tal não se verifica. 
60 Já quanto ao nome próprio, são extremamente raros os nomes andróginos e os que existem são pouco usados, ${ }^{17}$ pelo que o sistema tende a diferenciar os dois géneros precisamente no aspecto em que mais essencializa. É sobretudo nos contextos de maior criatividade antroponímica (p. ex. no Brasil popular) que se encontram ocorrências de ambiguidade de género no nome conducentes a estigmatização. Mas o problema limitase ao nome oficial, já que as possibilidades de exploração de androgenia inscritas nos outros nomes (alcunhas, hipocorísticos, etc.) são frequentes e não causam incómodo a ninguém porque estão silenciadas pela maior essencialidade do nome oficial.

61 Nesse aspecto, tanto a lei como o sentimento público "protegem" as pessoas da ambiguidade de género com muito empenho. Urge notar que não há nada de necessário nesta "protecção" - se a coisa é vista como "protecção" não é porque a ambiguidade de género não seja corrente na experiência humana (sabemos que é - cf. Pina Cabral 2003). No entanto, todos os entrevistados apresentam a questão como "protecção" do valor essencial da pessoa (cf. Schritzmeyer 2007). A essencialidade de género está inscrita no nome próprio de forma tão marcante que, mesmo em casos de alteração de sexo, o sistema legal se mostra muito renitente em aceitar a alteração da indicação de género do nome (sobrepondo-se aí o género à evidência corporal do sexo). Pelo contrário, um sistema legal como este que tudo faz para impedir as pessoas de mudar o seu nome próprio, está pronto a corriqueiramente permitir alteração de nome próprio em situações onde a conotação de género possa ser errada ou ambígua (e aí a evidência física já é tratada como determinante - Schritzmeyer 2007). O nome próprio genderiza a pessoa, passe o neologismo.

Dito isto, há que assinalar que, apesar de os nomes lusófonos serem marcados pela diferenciação de género, relativamente a outras tradições antroponímicas, o seu uso é bastante igualitário. Há que atender ao facto de, por exemplo, não ocorrerem aqui processos sistemáticos de silenciamento antroponímico feminino, tais como os que Rubie Watson identificou para o sul da China (1986). Assim, no todo, o sistema assume um paralelismo essencial entre os géneros mas, ao mesmo tempo, realiza uma diminuição relativa do género feminino. A antroponímia lusófona parece reflectir as regras gerais da gramática das línguas ibéricas, na qual os géneros são diferenciados quando usados no singular ou no colectivo intragéneros mas, sempre que ocorre um colectivo que integre membros dos dois géneros, o género masculino é englobante.

Quer dizer, a hegemonia simbólica masculina coabita com um essencial igualitarismo que, ao nível da família, atribui a liderança sobre a casa não a um indivíduo mas a um casal (cf. Pina Cabral 1991: 153-segs.). As regras de transmissão do sobrenome, tanto no seu relativo laxismo como no seu patriarcalismo mitigado, reflectem precisamente este processo. E, mais uma vez, agora em relação aos géneros, encontramo-nos perante mais um binómio assimétrico. Só que, contrariamente aos binómios anteriormente analisados, este não é constituído por adição nem por subtracção. Aqui, a assimetria é constituída por englobamento: ao género masculino é atribuído uma maior anterioridade. A melhor descrição do funcionamento do processo é mesmo a que é feita através do mito fundador do Adão e Eva: Adão é o primeiro "homem" e Eva é criada a partir dele (cf. Pina Cabral 1989: 109-111). Esta cena, desenhada sob forma de um corpo de homem do qual sai, androginamente, uma mulher é um lugar-comum dos tectos pintados dos conventos franciscanos por todo o Portugal e o Brasil.

Este processo aproxima-se do modelo de hierarquia por englobamento de opostos que Louis Dumont propõe na sua famosa obra Homo Hierarchicus (1967). Contrariamente ao 
modelo de binarismo proposto por Lévi-Strauss, em que os opostos se encontravam em situação simétrica, Dumont propõe um modelo em que a binaridade coexiste com a capacidade de englobamento de um dos pólos pelo outro. Este último, portanto, é mais abrangente que o que é englobado. Este modelo permite-nos dar forma à maneira como os sistemas antroponímicos ibéricos atribuem uma essencial igualdade aos géneros combinando-a com uma primacidade simbólica masculina (cf. Pina Cabral 2003: 55--88). Não o adoptarei integralmente só na medida em que se apresenta como sincrónico, o que não corresponde ao funcionamento do sistema ideológico ibérico que tento descrever. Aqui, o englobamento funciona de forma temporalizada - é o pressuposto de anterioridade masculina que realiza o englobamento. Nos nomes de origem ibérica, tal como no mito de Adão e Eva, a ligação masculina vem antes e dura mais. ${ }^{18}$

\section{Conclusão}

O nome inscreve a pessoa no mundo de forma durável; essencializa a pessoa efectuando uma triangulação entre o self e o corpo. $O$ elo entre ambos é inscrito no mundo por meio do nome, tornando-se reconhecível por outros. No caso da antroponímia lusófona, o processo envolve os três binómios a que nos referimos: nome próprio/sobrenome; nome verdadeiro/outros nomes; masculino/feminino. Todos estes correspondem a dinâmicas de desequilíbrio essencial (pessoa vs. família; pessoa vs. Estado/Igreja; pessoa vs. homem/ mulher). Quer dizer, estabelecem a maior ou menor essencialidade (realidade relativa) de um pólo sobre o outro, mas não apagam nenhum deles.

Ao aceitar o nome que lhe deram ainda antes de se conhecer a si mesma, a pessoa sujeita-se logo à partida a ser definida por relação a três instâncias de dominação: por relação à família, por relação ao Estado/Igreja e por relação à hegemonia masculina. Ao mesmo tempo, estas dependem da pessoa para a sua própria existência. Estamos, pois, perante processos de dominação hegemónica, quer dizer formas de dominação legitimada (cf. Pina Cabral 2000). De facto, como a pessoa não preexiste ao acto de nomeação e as instâncias de dominação não sobreviveriam sem a pessoa, o processo é mutuamente constitutivo. Dominação, aqui, portanto, remete mais para a docilidade como dispositivo constitutivo humano ${ }^{19}$ do que para violência, no sentido que atribuem ao conceito os neofoucauldianos.

Desde a Época Moderna, o nome europeu individua - nesta medida, esta tradição diverge muito de outras que a antropologia tem estudado. 0 nome promove que a pessoa se apresente como tendo "naturalmente" uma presença independente das instâncias de dominação que a criam. Por meio do primeiro binómio, a pessoa apresenta-se como unitária enquanto a família é uma colectividade. O segundo binómio não reduz a centralidade da pessoa, antes pelo contrário, posiciona-a como a instância natural de cidadania ou de espiritualidade (a alma). No caso do terceiro binómio, por sua vez, o processo de englobamento feminino pelo masculino assenta sobre uma formulação da essencial pessoalidade dos membros de ambos os géneros (ambos são, igualmente, parte da categoria genérica "homem").

68 A aparência de inevitabilidade da pessoa-enquanto-indivíduo que emerge da tradição antroponímica lusófona é um produto da legitimação da dominação familista, estatista e patriarcalista. Não há nada de "residual", portanto, na construção social da pessoa ocidental, como sustentava Louis Dumont. Todo o contrário. O que existe é um poderoso aparelho ideológico que, através do funcionamento das assimetrias que 
identificámos, atribui a aparência de indivíduo a pessoas que nunca deixam de ser socialmente construídas. Não se trata de uma representação artificiosa (uma ficção ideológica) pela simples razão que também não há essencialidade nas instâncias de dominação que criam a pessoa.

Os nomes de pessoa, tal como eles evoluíram na Península Ibérica e, mais ou menos contemporaneamente, se espalharam pelo mundo através do processo de expansão colonial, são um instrumento social para constituir pessoas com características determinadas. A pessoa unitária é naturalizada através de um processo de citação, remetendo para as três instâncias referidas. A pessoa é essencializada por meio da citação mas não fica fechada nela. $O$ nome está permanentemente sujeito à exploração dos ecos nominativos, processo que garante que não sufoque a pessoa, mas a abra ao mundo.

Chegado a este ponto, o leitor poderá perguntar-se o que há de especificamente lusófono com estes vectores estruturantes, na medida em que eles podem ser identificados em praticamente toda a Europa e até, mais geralmente, na Eurásia. E, de facto, assim é. As implicações a retirar do seu funcionamento específico em cada contexto, porém, são consideráveis. ${ }^{20}$ Mais sumariamente, podemos afirmar que a antroponímia lusófona moderna é em quase tudo idêntica à hispanófona e que, por conseguinte, estamos a identificar um sistema ibérico (ou, mais propriamente, pósibérico). ${ }^{21}$ Por outro lado, a comparação com os sistemas europeus transpirenaicos revela consideráveis diferenças que merecem ser identificadas.

71 Em primeiro lugar, a antroponímia moderna de raiz ibérica associa mais vincadamente o nome à "alma"; a essencialidade da pessoa demarca-se através do sagrado cristão. Em segundo lugar, existe uma muito maior ênfase sobre a imutabilidade do nome, que se prende com a forte subordinação do indivíduo a instâncias burocráticas (estatais e canónicas) que retiram força às instâncias comunitárias intermédias. Em terceiro lugar, a tendência para a polionomásia é uma característica determinante destes sistemas.

Em relação a esta última, há três aspectos a identificar: o primeiro é que ela permite um jogo de diferentes recortes do nome, que liberta parcialmente o indivíduo dos perigos da excessiva essencialidade do nome; o segundo é a bilateralidade dos sobrenomes, que abre possibilidades de constituição familiar que não estão disponíveis no âmbito da patrilateralidade compulsiva dos sistemas transpirenaicos; a terceira é a forma como a polionomásia facilita uma acumulação antroponímica de prestígio social. Cria-se, assim, um espectro de nomeação que parte dos que não têm "nome escrito", passa aos que só têm nome próprio, aos que têm um nome próprio como sobrenome, aos que só têm um sobrenome, ao jogo burguês dos sobrenomes duplos, até aos que chegam a ter cinco, seis e mais sobrenomes. É assim que, em todos os contextos lusófonos, o nome é um dos mais poderosos veiculadores de pertença de classe.

\section{BIBLIOGRAFIA}

DUMONT, Louis, 1967, Homo Hierarchicus: Essai sur le Système des Castes. Paris, Gallimard. 
FARDON, Richard, 1996, "Contrast and comparison: Notes from a Middle-Belt West African practice”, dissertação inaugural como professor. Londres, SOAS Pamphlet.

FROIS, Catarina, 2007, "Nome e anonimato nas associações de 12 passos", em João de Pina Cabral e Susana de Matos Viegas (orgs.), op. cit., pp. 291-312.

LÉVI-STRAUSS, Claude, 1977, L'identité. Paris, Grasset.

LOPES DA SILVA, Aracy, 1986, Nomes e Amigos: Da Prática Xavante a uma Reflexão sobre os Jê. São Paulo, FFLCH-USP.

MACHADO, Ana Maria, 1991 [1976], Recado do Nome: Leitura de Guimarães Rosa à Luz do Nome de seus Personagens. São Paulo, Martins Fontes Ed.

MAUSS, Marcel, 1985 [1938], "A category of the human mind: the notion of person; the notion of self”, em M. Carrithers, S. Collins, e Steven Lukes (orgs.), The Category of Person: Anthropology, Philosophy, History. Cambridge, Cambridge University Press, pp. 1-25.

MAUSS, Marcel, 1968 [1929], "L'âme, le nom et la personne”, em Euvres, Vol. 2. Paris, Editions de Minuit, pp. 131-135.

MAYBURY-LEWIS, David, 1974, Akwe-Shavante Society. Nova Iorque, Oxford University Press.

PEDROSO DE LIMA, Antónia, 2007, “Intencionalidade, afecto e distinção: As escolhas de nomes em famílias de elite de Lisboa”, em João de Pina Cabral e Susana de Matos Viegas (orgs.), op. cit., pp. 39-62.

PIMENTA, José da Costa, 1986, Filiação. Coimbra, Coimbra Editora.

PINA CABRAL, João de, 2007a, "A pessoa e o dilema brasileiro: uma perspectiva anticesurista", Novos Estudos CEBRAP 78, pp. 95-112.

PINA CABRAL, João de, 2007b, “Mães, pais e nomes no Baixo Sul (Bahia, Brasil)”, em João de Pina Cabral e Susana de Matos Viegas (orgs.), op. cit., pp. 63-88.

PINA CABRAL, João de, 2005a "La soglia degli affetti: considerazioni sull'attribuzione del nome e la costruzione sociale della persona", Annuario di Antropología, 5 (6). Roma, Meltemi, pp. 151-172.

PINA CABRAL, João de, 2005b, “Identidades inseridas: algumas divagações sobre identidade, emoção e moralidade”, Revista Portuguesa de Psicanálise, 26 (1). Lisboa, pp. 97-118.

PINA CABRAL, João de, 2003, o Homem na Família: Cinco Ensaios de Antropologia. Lisboa, Imprensa de Ciências Sociais.

PINA CABRAL, João de, 2002, Between China and Europe: Person, Culture and Emotion in Macao. Londres e Nova Iorque, Continuum Books/Berg (LSE Anthropology Series 74).

PINA CABRAL, João de, 2000, “A difusão das margens: margens, liminaridade e contradições”, Análise Social, 153, Lisboa, pp. 865-892.

PINA CABRAL, João de, 1991, Os Contextos da Antropologia. Lisboa, Difel.

PINA CABRAL, João de, 1989, Filhos de Adão, Filhas de Eva: A Visão do Mundo Camponesa do Alto Minho. Trad. de Paulo Valverde. Lisboa, Dom Quixote.

PINA CABRAL, João de, 1984, "Nicknames and the experience of community", correspondência em Man, n. s., 19 (1), pp. 148-150.

PINA CABRAL, João de, e Susana Matos Viegas (orgs.), 2007a, Nomes: Género, Etnicidade e Família. Coimbra, Almedina. 
PINA CABRAL, João de, 2007b, "Nomes e ética: uma introdução ao debate", em João de Pina Cabral e Susana de Matos Viegas (orgs.), op. cit., pp. 13-38.

PINA CABRAL, João de, e Antónia Pedroso de Lima, 2005, “Como fazer uma história de família: um exercício de contextualização social”, Etnográfica, 9 (2), Lisboa, pp. 355-388.

SANSI-ROCA, Roger, 2007, "The fetish in the lusophone Atlantic”, em Roger Sansi-Roca, Nancy Naro e David Treece (orgs.) Cultures of the Lusophone Black Atlantic. Londres, Palgrave Macmillan, pp. 19-38.

SCHRITZMEYER, Ana Lúcia Pastore, 2007, “Nomes em julgamento: práticas judiciárias patronizando identidades sexuais", em João de Pina Cabral e Susana de Matos Viegas (orgs.), op. cit., pp. 89-120.

TRAUBE, Elizabeth G., 1986, Cosmology and Social Life: Ritual Exchange Among the Mambai of East Timor. Chicago, The University of Chicago Press.

WATSON, Rubie, 1986, "The named and the nameless. Gender and person in Chinese society", American Ethnologist, 13 (4), Washington, pp. 619-31.

VALVERDE, Paulo J., 2000, Máscara, Mato e Morte. Lisboa, Celta.

\section{NOTAS}

1. Fardon, aliás, reconhece-o: "se a descrição é contrastiva, e os contrastes potenciais são infinitos, em que bases poderá fundamentar-se um autor para truncar todas as diferenças que poderiam ser escolhidas, para descrever de forma finita?" (1996: 6).

2. Mesmo que os nomes em causa recorram a vocábulos que não são de origem portuguesa como exemplifica o caso apresentado neste volume por Gregório Firmino.

3. Cf. Pina Cabral (1991: caps. 7 a 9; 2002: cap. 7; 2005a; 2007b).

4. Vejam-se os exemplos de sobrenomes comuns como Camelo, Nabo, Grilo, Feio, Rato, etc.

5. Aliás, quando os jornalistas me entrevistam sobre o assunto, a conversa acaba sempre na risota dos "nomes esquisitos" - sempre nomes próprios, claro, nunca nenhum jornalista se lembrou de publicar uma lista de sobrenomes que pudessem ser caricatos.

6. Digo "parque", já que "património" parece ser reservado pelos juristas só para os nomes próprios.

7. Na minha compreensão, o "individualismo" do sistema é uma característica dele que não obnubila de forma alguma, nem torna "residual", a natureza construída e compósita da pessoa humana (cf. Pina Cabral 2007a). Não é esta, porém, a ocasião para desenvolver mais longamente este argumento.

8. "JK", "FCH" ou "ACM", por exemplo, simbolizam por letras maiúsculas a grandeza do nome.

9. Se bem que a Igreja Católica Romana, agora, prefira adiar o baptismo, só o faz num momento em que o acto de consolidação nominativa foi afastado decisivamente da pia baptismal para o cartório do Registo Civil.

10. 0 caso das mulheres que adicionam os sobrenomes dos maridos quando se casam não é aqui considerado porque remete para os sobrenomes, pelo que não causa efeito de excepção. Trata-se, aliás, de uma prática que só se vulgarizou muito tardiamente, como Nuno Gonçalo Monteiro demonstra.

11. Note-se que, se na China há maior liberdade para alterar o nome próprio, não é porque haja maior liberdade de movimentação social da pessoa, mas sim porque a dinâmica entre nome próprio e sobrenome é muito diferente nas sociedades neoconfucianas, onde o princípio de descendência agnática continua a ser muito forte (cf. Pina Cabral 2002: 79-204). 
12. Que, chamo a atenção, não estou a criticar. Tantos disparates apressados se têm escrito sobre a matéria de há uns anos a esta parte que parece importante fazer esta ressalva (cf. Pina Cabral e Pedroso de Lima 2005).

13. No seu famoso texto sobre a categoria de pessoa (cf. Mauss 1985 [1938] e Pina Cabral 2007a).

14. “A alma, o nome, a pessoa" - Mauss (1968 [1929]).

15. Assinalo com o itálico um curioso implícito da frase de Elizabeth Traube: ela usa formas mambai, sim, mas metaforizando-as ("como se"), pois não abdica da sua constituição europeia de pessoa. As citações acima de Maybury-Lewis exemplificam o mesmo processo. Estas observações devem levar--nos a meditar sobre a complexidade das condições de realização de trabalho etnográfico com observação participante.

16. A palavra descreve um tipo físico.

17. Os casos ligados ao culto mariológico em que o nome de Maria é conjugado com nomes de santos masculinos (Manuel, João e José e poucos mais) não podem ser considerados andróginos, já que não existe qualquer ambiguidade - se Maria é o primeiro nome, é mulher, se é o segundo nome, é homem.

18. Na década de 1930, os sistemas legais brasileiro e português passaram a instituir um esquema contrário ao que era mais comum anteriormente entre nós, em que o sobrenome patrilateral vinha em primeiro lugar. Levanta-se a hipótese de esta mudança ter sido uma resposta à internacionalização. $O$ uso comum britânico e francês faz com que os nomes intermédios caiam ou sejam permanentemente reduzidos à condição de iniciais. Assim, ao remeter o sobrenome do pai para o fim, os juristas do período republicano tentavam impedir que a pessoa lusófona fosse corriqueiramente referida pelo sobrenome da mãe em contextos internacionais. Tratar-se-ia, pois, de uma forma de preservar a lógica anterior do sistema face à globalização.

19. Remetendo para o sentido que os filósofos analíticos dão ao conceito de "caridade" - como na noção davidsoniana de "caridade interpretativa".

20. Remeto o leitor para a comparação com a China no funcionamento do binómio nome próprio / sobrenome (cf. Pina Cabral 2002: 141-158) assim como para a importância da existência de um princípio de descendência agnática na China e da sua ausência em Portugal (Pina Cabral 2002: 179-204; e 1991: 143-153).

21. A diferenciação histórica existente entre processos de nomeação informal em diferentes regiões da Península mereceria amplamente um estudo recorrendo a comparação controlada (cf. Pina Cabral 1984).

\section{RESUMOS}

A proposta central deste ensaio é que a tradição antroponímica lusófona constitui um fenómeno de regionalidade sociocultural que permite um exercício da comparação contrastiva. Desde as mudanças que ocorreram no início da Época Moderna, o nome lusófono promove que a pessoa se apresente como tendo "naturalmente" uma presença independente das instâncias de dominação que a criam. O campo é estruturado por três binómios assimétricos: o binómio nome próprio / sobrenome, que apresenta a pessoa como unitária, enquanto a família assume o aspecto de colectividade; o binómio nome oficial / outros nomes, que posiciona a pessoa como a instância elementar da cidadania e da espiritualidade (a alma); o binómio masculino / feminino, que cria um processo de englobamento do feminino pelo masculino. 
This essay approaches the Lusophone tradition in personal naming as a kind of sociocultural regionality, allowing for subsequent contrastive comparison. Ever since the changes that took place at the onset of the Modern Era, Lusophone names can be seen to promote the person as possessing a "natural" existence when faced with the primary instances of domination which relate with it. Three assymetric bynomials structure the field: the opposition between first name and surname, presents the person as unitary when faced with the family which, thus, becomes a collective phenomenon; the opposition between official name versus other names places the person as the building block of citizenship and spirituality (the soul); the opposition masculine/feminine creates a process of encompassment of the later by the former.

\section{ÍNDICE}

Keywords: lusophone, personal names, controlled comparison, domination

Palavras-chave: lusofonia, nomes de pessoa, comparação controlada, dominação

\section{AUTOR}

\section{JOÃO DE PINA-CABRAL}

Insituto de Ciências Sociais, Universidade de Lisboa, pina.cabral@ics.ul.pt 